\title{
Decisões sobre o prazo de endividamento de empresas brasileiras de capital aberto - um modelo ajustado com base em teorias de imperfeições do mercado e ambiente macroeconômico (2000-2011)
}

\section{Decisions about debt maturity of Brazilians companies - an adjusted model underpinned in market imperfections theories and macroeconomic environment (2000 -2011)}

FÁBIO VIANA DE MOURA Universidade Federal de Ouro Preto

\section{RESUMO}

O principal objetivo deste trabalho foi o de identificar fatores que influenciam o prazo do endividamento de empresas brasileiras não financeiras de capital aberto. Com base em teorias de imperfeições do mercado, testou hipóteses sobre até que ponto as oportunidades de investimento, o tamanho e a qualidade da empresa, as despesas tributárias, a regulamentação do setor, a alavancagem financeira e, adicionalmente, a conjuntura macroeconômica afetariam a decisão das empresas observadas pela escolha de uma maior proporção de endividamento de curto prazo. Após ajustes na base de dados, foi observada uma amostra de 386 empresas, no período compreendido entre 2000 e 2011. O total das observações analisadas foi de 2385, organizadas em um painel não balanceado. Com o auxílio do software $R$-project, foram estimados e testados modelos de regressão múltipla: OLS pooling, de efeitos fixos e de efeitos aleatórios. Os testes indicaram um melhor ajuste para o modelo de efeitos fixos, que apresenta estimativas de coeficientes de regressão teoricamente consistentes 
com as predições das teorias que fundamentam o trabalho. $\mathrm{O}$ modelo testado mostra que hipóteses construídas com base em teorias de imperfeições de mercado e ambiente macroeconômico são relevantes para explicar o prazo de endividamento de companhias brasileiras.

Palavras chaves: Imperfeições do Mercado. Prazo de Endividamento. Instabilidade Macroeconômica.

\section{Abstract}

The main objective of this study was to identify factors influencing the debt term of Brazilian non-financial listed companies. Based on theories of market imperfections, this work tested hypotheses about the extent to which investment opportunities, the size and quality of the company, tax expenses, industry regulation, financial leverage and, in addition, the macroeconomic environment would affect the decision enterprises by choosing a higher proportion of short-term debt. After adjustments in the database, whose source was the Economática system, a sample of 386 companies was observed in the period between 2000 and 2011. The total number of observations analyzed in an unbalanced panel was 2385. Using R-project software, multiple regression models were estimated and tested: OLS pooling, fixed effects and random effects. The tests indicated a better fit for the fixed effects model, which presents estimates of regression coefficients theoretically consistent with the predictions of the theories of the market imperfections. It is worth noting that as expected, the variable of macroeconomic instability control is statistically significant in explaining the variation in the debt of companies observed.

Key words: Market imperfections theories. Maturity of corporate debt. Macroeconomic instability.

\section{INTRODUÇÃo}

Os aperfeiçoamentos teóricos relativos aos custos de transação (Coase, 1937) e aos problemas de assimetria da informação (Akerlof,

1978) deram base para desenvolvimento da tipologia do contrato de agência, seus problemas e custos (Jensen \& Meckling, 1976). Fundamentados em tais contornos teóricos, estudos em economia, finanças e contabilidade passaram a ter um fértil terreno para cons- 
truir hipóteses visando explicar a variação no comportamento das empresas no que concerne a uma vasta gama de fenômenos. Dentro dessa grande linha de investigação empírica, muitos estudos têm se destinado a compreender os fatores que afetam o prazo do endividamento das empresas, abordando outras variáveis além daquelas relacionadas única e exclusivamente ao risco de falência.

Especialmente na área de finanças, há uma reconhecida e testada literatura que tem se mostrado empiricamente consistente ao explicar o que determinada a maturidade do endividamento de empresas. Nesse contexto, podemos destacar os trabalhos de Myers (1977) , Smith Jr (1986), Flannery (1986), Barclay e Smith Jr (1995), Brick e Ravid (1985) e, no Brasil, o de Nakamura, Jucá, e Bastos (2011). Myers (1977) demonstra como a relação de agência entre acionistas e credores pode levar ao problema denominado de subinvestimento, e como este, por sua vez, pode fazer com que empresas prefiram se endividar com dívidas de curto prazo. Smith Jr (1986) explica como empresas de setores mais regulamentados optariam mais provavelmente por endividamento de longo prazo. Já Barclay e Smith Jr (1995) descrevem por que fatores empresas de menor porte tenderiam a contratar mais dívidas de curto-prazo. Flannery (1986) destaca o papel dos problemas de assimetria de informação entre gerentes e acionistas e o de sinalização sobre os riscos da empresa, como fator determinante do prazo de endividamento. Suas hipóteses predizem que firmas de melhor qualidade em relação a esses aspectos, tenderiam a emitir/contratar mais dívidas de curto prazo. Por fim, devemos mencionar o trabalho Brick e Ravid (1985) que tem como mérito explicar como diferentes expectativas quanto ao custo da dívida podem levar empresas optarem por se endividarem ou no curto ou longo prazo.

Conforme exposto por Nakamura, Jucá, e Bastos (2011), tais estudos lançaram luz sobre possíveis aspectos ainda pouco discutidos e que têm se mostrado empiricamente relevantes para o entendimento sobre fatores que impactam as decisões de empresas em relação ao prazo das dívidas que elas contratam. Tal literatura tem ganhado espaço no mundo e no Brasil. Muitos trabalhos têm sido desenvolvidos com o intuito de realizar testes teóricos, aperfeiçoar metodologias, e de melhorar a especificação dos modelos 
ajustados com base em tais ideias. Recentemente, pesquisas sobre o tema têm considerado o efeito de crises financeiras conjunturais sobre a maturidade do endividamento de empresas (Almeida, Campello, Laranjeira, \& Weisbenner, 2009; Choi, Hackbarth, \& Zechner, 2018). Nesse sentido, pode-se se dizer que o presente trabalho se enquadra neste escopo e, visando melhorar a especificação de modelos de predição da maturidade do endividamento de empresas brasileiras, ele incorpora uma nova variável, especialmente uma que visou captar a restrição de acesso de empresas a crédito, em períodos em que o Brasil vivenciou uma desaceleração das operações de crédito a empresas.

Deste modo, este trabalho almejou contribuir para o desenvolvimento desta linha de pesquisa. Mais especificamente, ele incorpora, testa e valida em suas análises o efeito de variáveis ainda não consideradas por estudos realizados no Brasil e que se mostram importantes para ajudar a explicar a decisão de empresas por endividamento de curto prazo. Ou seja, além das variáveis que teoricamente influenciariam a opção pela maturidade das dívidas das empresas, esta pesquisa levou em consideração uma variável adicional, que buscou captar o impacto aspectos exógenos, relacionados ao ambiente no qual as empresas operam, sobre a opção pelo endividamento de curto prazo de empresas brasileiras. Essa variável adicional capturou períodos de instabilidade econômica e consequente problemas de oferta de crédito. Deste modo, a presente análise testou também a hipótese de que em períodos de crise econômica, especialmente aqueles motivados pela desconfiança do mercado, tal como acontecido em 2002 e 2008, empresas teriam menos acesso a fontes de recursos de longo prazo, o que afetaria diretamente a composição do prazo de seu endividamento.

Visando alcançar propósitos previamente definidos, o texto deste trabalho se estrutura da seguinte maneira: a próxima seção apresenta a fundamentação teórica que justifica a inclusão das variáveis incorporadas no ajuste do modelo; a subsequente descreve os procedimentos metodológicos empreendidos; a posterior apresenta e analisa os resultados e; por fim, a derradeira tece as considerações finais sobre os objetivos, achados, limitações e outros elementos entendidos como necessários à interpretação dos resultados apresentados. 


\section{REFERENCIAL TEÓRICO}

\subsection{Oportunidades de investimentos}

Segundo Myers (1977) a relação de agência estabelecida entre acionistas e credores, suas consequências e problemas dela decorrentes podem acarretar a indesejada situação do subinvestimento. Acionistas precisam suportar todos os custos que a companhia incorre para rolar suas dívidas, enquanto credores obtêm seu fluxo de caixa integralmente (He \& Xiong, 2012, p. 3). Deste modo, o subinvestimento aconteceria porque acionistas evitariam aprovar planos de investimentos com valor presente líquido positivo quando o endividamento fosse muito alto; haja vista que, em tal situação, grande parte dos lucros decorrentes da implantação do projeto seria destinada ao pagamento do custo da dívida, sobrando, desta maneira, uma pequena parcela do resultado para os acionistas.

Entretanto, e como frisado por Barclay e Smith Jr (1995), em tal ambiente teórico, endividamento de curto prazo serviria como um remédio para o problema do subinvestimento. Seguindo tais ideias, pode-se argumentar que empresas que têm crescentes oportunidades de investimento tenderiam a optar com maior probabilidade por endividamento de curto prazo, visto que a fluxo de caixa gerado pelas opções de investimento realizadas aconteceriam após resgate ou liquidação das dívidas, remanescendo assim, para os acionistas, uma maior parcela do resultado de tais projetos (Titman \& Wessels, 1988). Deste modo, é possível testar empiricamente se empresas com crescentes oportunidades de investimento seriam mais susceptíveis de contratar ou emitir dívidas de curto prazo do que empresas com baixas oportunidades de investimento. Isso aconteceria porque empresas com crescentes oportunidades de investimento buscariam mitigar os efeitos e custos decorrentes do problema do subinvestimento. Corroborando tais ideais, resultados de pesquisas mais recentes têm demonstrado haver uma correlação entre atuais oportunidades de investimento e um excesso de endividamento de curto prazo (Diamond \& He, 2014).

\subsection{Regulamentação}

Outro fator que teoricamente afetaria o endividamento das empresas seria a regulamentação. Smith Jr (1986) argumenta que 
gerentes de empresas regulamentadas, que estão sujeitas a um maior monitoramento, teriam menos discrição sobre as futuras decisões de investimento do que gerentes de empresas que operam em setores não regulamentados (Barclay \& Smith Jr, 1995).

Por essa forma de pensar, há um esperado impacto da regulamentação do setor no qual a empresa opera e o prazo do endividamento, de modo que empresas que operam em setores mais regulamentados contratariam ou emitiriam dívida de longo prazo com maior probabilidade do que empresas que operam em setores menos regulamentados. Isso ocorreria porque a regulamentação reduziria a discrição gerencial que, por sua vez, diminuiria o efeito adverso do endividamento de longo prazo sobre as políticas de financiamento da empresa (Barclay \& Smith Jr, 1995; Smith Jr, 1986).

\subsection{Tamanho da empresa}

Como demonstrado por Rauh (2006), empresas pequenas são mais susceptíveis a encontrar dificuldades para acessar fontes de financiamento. Barclay e Smith Jr (1995) apontam que, por várias razões, o tamanho da empresa seria em grande medida relacionado com o prazo de vencimento de suas dívidas. O custo de emissões públicas de títulos de dívida, por exemplo, seria um dos fatores responsáveis por isso. Pois, como tais transações têm altos custos fixos (por emissão), emissões de dívida de maior valor absoluto, realizadas com mais frequência por empresas maiores, implicariam menores custos totais por emissão. Nesse sentido, grandes empresas seriam mais susceptíveis a emitir dívidas de longo prazo do que empresas pequenas. Ademais, empresas maiores têm maior facilidade de acesso ao mercador de capitais (Titman \& Wessels, 1988) e empresas pequenas são geralmente impedidas de acessar mercados de dívidas de longo prazo, uma vez que a proporção de seus ativos que podem ser oferecidos em garantia para futuras oportunidades de investimento e relativamente menor (Whited, 1992). Tais aspectos seriam responsáveis por uma direta relação entre tamanho da empresa e o prazo de maturidade de suas dívidas (Ozkan, 2000).

Adicionalmente, empresas menores enfrentam o problema relacionado ao conflito entre acionistas e credores (Smith Jr \& Warner, 1979). A emissão de dívidas de longo prazo é mais frequentemente 
acompanhada de restrições contratuais sobre a distribuição de dividendos, fazendo com que empresas menores tendessem a emitir mais dívidas de curto prazo, uma vez que essas carregam consigo, na maior das vezes, menores barreiras para participação dos acionistas nos fluxos de caixa da empresa. Deste modo, os problemas de agência presentes no conflito entre acionistas e credores podem ser reduzidos via emissão de dívidas de curto prazo (Barnea, Haugen, \& Senbet, 1980), o que tem sugerido que empresas pequenas com mais severos problemas de agência recorreriam a endividamento com menor prazo de maturidade com o objetivo de mitigar os custos decorrentes desses problemas (Ozkan, 2000).

Ante o discutido acima, em razão de empresas menores terem, de certa forma, (1) maiores oportunidades de investimento; (2) proporcionalmente maior o custo total da emissão de dívidas de longo prazo; (3) mais dificuldade de acesso a mercados de dívida de longo prazo; e (4) problemas de agência; pode-se esperar elas tendam a contratar mais dívidas de curto prazo do que empresas maiores.

\subsection{Problemas de assimetria de informação}

Questões de assimetria de informações repercutiriam na decisão corporativa de emitir dívidas de curto ou de longo prazo. Nessa direção, Flannery (1986) examina as implicações da sinalização na escolha pelo prazo de vencimento de dívidas, feita por empresas com certas características. Flannery (1986) parte da suposição de que quando investidores e gerentes ou controladores têm a mesma informação sobre as perspectivas da companhia, as obrigações da empresa seriam precificadas de modo a tornar indiferente para empresa optar por dívidas de curto ou de longo prazo. Alternativamente, quando agentes internos detêm mais informações que os externos, eles escolheriam emitir ou contratar espécies de dívida que o mercado tendesse a precificar a um valor maior do que seria adequado, se considerado todas as informações sobre os riscos associados à transação. Em função disso, investidores racionais buscariam inferir a informação retida pelos insiders via análise da estrutura financeira da empresa.

Nesse sentido, Flannery (1986) pontua que gestores de empresas de alta qualidade tenderiam a emitir mais dívidas de curto 
prazo do que os gestores de empresas de baixa qualidade. Como demonstrado por Nakamura, Jucá, e Bastos (2011), emitindo dívidas de curto prazo, os gestores das empresas mais sólidas estão se submetendo ao risco de terem que, necessariamente, refinanciar suas dívidas após novas informações. Sendo tais informações positivas, o que acontecerá na maior parte das vezes com empresas de boa qualidade, o custo da dívida refinanciada seria menor do que o da contratada anteriormente, ceteris paribus.

Assim, como predito por Flannery (1986), Barclay e Smith Jr (1995), Nakamura, Jucá, e Bastos (2011) confirmam em seu trabalho, com significância estatística, que a qualidade da firma é inversamente proporcional à maturidade de suas dívidas. Ou seja, empresas de melhor qualidade tendem a emitir ou contratar mais dívidas de curto prazo, enquanto que empresas de má qualidade tendem a optar por dívidas de longo prazo.

\subsection{Despesas tributárias}

Brick e Ravid (1985) afirmam a expectativa sobre o custo da dívida de curto e de longo prazo afetaria a escolha da organização por tais tipos de dívida, dado o efeito que tal custo teria sobre os respectivos benefícios tributários decorrentes a alavancagem financeira. Eles concluem que empresas prefeririam mais dívidas de longo prazo quando houvesse uma expectativa de crescimento do custo da dívida ao longo do tempo.

Já para Kane, Marcus, e McDonald (1985) a estrutura ótima de maturidade das dívidas seria determinada por uma troca entre as vantagens tributárias do financiamento bancário versus o risco de falência e a flutuação dos custos de emissão de dívidas. Segundo tais autores, o prazo ótimo das dívidas aumentaria à medida que as vantagens tributárias das dívidas bancárias diminuíssem, que a flutuação dos custos de emissão de dívidas aumentasse e que a volatilidade do valor da empresa reduzisse.

No Brasil, algumas pesquisas têm sido elaboradas com o objetivo de testar as relações teóricas acimas descritas. Nakamura, Jucá, e Bastos (2011), por exemplo, testam o efeito de oito variáveis, em uma amostra de 38 empresas, sobre a maturidade do endividamento das empresas. Utilizando dados em painel, relativos ao período compreendido entre 
2002 a 2007, eles encontram relações estatisticamente significativas para cinco das variáveis preditoras consideradas. Entretanto, apenas a que se refere ao efeito tributário, corrobora as hipóteses teóricas. As demais contradizem a relação predita pelas teorias.

Rochman, Laureano, e Eid Jr (2009) testaram, separadamente, a influência de variáveis no endividamento de longo (Exigível à Longo Prazo/Passivo Total) e curto prazo (Passivo Circulante/Passivo Total). As variáveis testadas são: composição dos ativos, liquidez, lucratividade, crescimento, tamanho, volatilidade e taxas de juros. Os resultados encontrados não são, em parte, consistentes com as teóricas de base acima descritas.

\section{Procedimentos Metodológicos}

\subsection{População, amostra e dados}

A população objeto de estudo deste trabalho compreendeu empresas brasileiras não financeiras de capital aberto que negociaram seus títulos na BMFBOVESPA no período compreendido entre 2000 e 2011, perfazendo um total de 521 empresas.

Os dados relativos às variáveis da amostra de empresas observada foram coletados através do sistema Economática. Após exclusão de observações de empresas que, em certos períodos, não apresentavam algum dado referente alguma das variáveis que entraram no ajuste do modelo, obteve-se uma amostra de 386 empresas, o que resultou em no total de 2.385 observações. Os dados foram organizados em painel não balanceado, haja vista que nem toda empresa que participou da análise apresentou observações em todos os anos que foram considerados pela pesquisa.

\subsection{Variável Dependente}

Tendo em vista que o objetivo do estudo consistiu em testar hipóteses construídas com base em teorias que se balizam nas imperfeições do mercado, visando identificar fatores que afetariam o prazo das dívidas contratadas pelas firmas; considerou-se como variável dependente a proporção entre as dívidas de curto prazo e as dividas totais, semelhantemente ao que foi feito por Barclay e Smith Jr (1995). 
Tal variável foi obtida diretamente das dimensões financeiras calculadas e disponibilizadas pelo sistema economática, denotada da seguinte forma:

$$
\operatorname{DivCP}=\frac{D I V C P}{D I V T O T}
$$

Onde DivCP capta a magnitude das dívidas de curto prazo ( DIVCP ) em relação às dividas totais (DIVTOT). Conforme predito pelas hipóteses subjacentes que deram lastro a este estudo, tal variável seria influenciada positiva ou negativamente pelas variáveis independentes que entraram no ajuste no modelo, a depender do caso. Tais relações serão apresentadas em posterior subseção do texto.

\subsection{Variáveis Independentes}

\subsubsection{Oportunidade de investimento}

A proxy de oportunidades de investimento $(O I)$ considerada por esta pesquisa, à semelhança do que feito pela literatura de referência (Barclay \& Smith Jr, 1995), é dada pela relação entre o valor de mercado dos ativos ( $V M A)$ das empresas observadas e o seu respectivo valor contábil ( $V C A$ ). Denotada da seguinte maneira:

$$
O I=\frac{V M A}{V C A},
$$

onde,

$$
\begin{aligned}
V M A= & (\text { valor de mercado do patrimônio líquido } \\
& - \text { valor contábil do patrimômio líquido })+V C A
\end{aligned}
$$

\subsubsection{Tamanho da empresa}

Outro fator que se esperou afetar o prazo do endividamento das empresas observadas foi o tamanho da empresa (T). Assim como considerado por Barclay e Smith Jr (1995), Nakamura, Jucá, e Bastos (2011) e outras pesquisas na área, tal variável foi medida 
pelo logaritmo natural da receita operacional líquida das empresas observadas.

\subsubsection{Regulamentação}

Segundo hipótese descrita anteriormente a regulamentação reduziria os problemas de agência vivenciados por companhias abertas e afetaria, portanto, a probabilidade de uma empresa contrair ou emitir dívidas de curto prazo. Essa dimensão será denotada doravante pela sigla: RE. Neste estudo, assim como fizeram Barclay e Smith Jr (1995), ela foi representada por uma variável dummy, que assumiu valor 01 nas observações de empresas que operam em setores regulamentados (prestadoras de serviços de interesse público, cedidos por concessão às empresas, tais como o transportes, o de energia elétrica, o de petróleo, o de telefonia etc.) e 0 nos demais casos.

\subsubsection{Qualidade da empresa}

Por questões de assimetria de informação e problemas de sinalização, a qualidade de uma empresa (QUAL) repercutiria na probabilidade da empresa contratar ou emitir dívidas de curto prazo ou de longo prazo. Seguindo orientações de trabalhos como o de Barclay e Smith Jr (1995) e o de Nakamura, Jucá, e Bastos (2011) o retorno por ação, dado pela relação entre lucro por ação do período observado e o do período posterior, foi a proxy utilizada por esta pesquisa. Deste modo, tal variável assume seguinte forma:

$$
Q U A L=\frac{\text { Lucro por ação } o_{t+1}}{\text { Lucro por açã } o_{t}}
$$

\subsubsection{Despesas tributárias}

A discussão precedente apresentou a hipótese de que as despesas tributárias atuais podem afetar a escolha da empresa pela emissão de dívidas de curto prazo. Por isso, este trabalho considerou que a alíquota efetiva de tributos (TRIB) seria uma boa proxy dos atuais gastos tributários. Tal variável foi calculada da seguinte forma: 


$$
\begin{aligned}
& \text { TRIB }=\text { Desp IR } / \text { LAIR } \\
& \text { onde: } \\
& \text { Desp IR = despesa com imposto de reda; } \\
& \text { LAIR = Lucro antes do Imposto de Renda. }
\end{aligned}
$$

\subsubsection{Alavancagem financeira}

Alavancagem Financeira (AF) foi outra variável que entrou no ajuste do modelo, servindo como variável de controle; em que se supõe que tal característica impactaria a escolha da empresa por dívidas de longo prazo ao invés de dívidas de curto prazo. Espera-se então que quanto mais alavancadas menos dívidas de curto prazo as empresas observadas apresentariam. A alavancagem financeira foi medida e considerada por este estudo, assim como feito por Nakamura, Jucá, e Bastos (2011), da seguinte maneira:

$$
\begin{aligned}
& A F= \frac{D C P+D L P}{V M A} \\
& \text { Onde: } \\
& D C P=\text { dívidas de curto; } \\
& D L P=\text { dívidas de longo prazo; } \\
& \\
& V M A=\text { valor de mercado dos ativos. }
\end{aligned}
$$

\subsubsection{Instabilidade Macroeconômica}

Outra variável de controle levada em consideração nos ajustes dos modelos testados foi a denominada por instabilidade macroeconômica (IM). A justificava para sua inclusão é a de que nos anos de instabilidade macroeconômica há, por consequência, uma menor oferta de crédito para as empresas, especialmente, a relativa a fontes de financiamento de longo prazo. Ou seja, em anos que poderiam ser assim caracterizados, empresas tenderiam a aumentar a proporção de suas dívidas de curto prazo.

Tal variável entrou no ajuste do modelo como uma variável dummy. Ela assumiu valor 01 nos anos nos quais houve desacele- 
ração da oferta de crédito em relação ao período anterior e 0 nos demais casos. Os dados sobre a oferta de crédito relativo ao período analisado foram extraídos do relatório de oferta de crédito, disponível no site do Banco Central do Brasil. Por esse critério, foram considerados como períodos de baixa oferta de crédito anos de 2002, 2003, 2009 e 2010.

\subsection{Método estatístico}

Em função da característica dos dados observados por este estudo, organizados em painel, o procedimento metodológico básico consistiu em ajustar os modelos de regressão múltipla, lançando mão dos métodos dos mínimos quadrados ordinários polling, de efeitos fixos e de efeitos aleatórios. Testando, posteriormente, as respectivas qualidades e adequações dos modelos ajustados, bem como de seus supostos, visando selecionar aquele cujos resultados encontrados pudessem ser considerados mais robustos econometricamente. A forma geral do modelo ajustado foi a seguinte:

$$
\begin{aligned}
& \operatorname{DivCP}_{i t}=\alpha_{i}+\beta_{O I} O I_{i t}+\beta_{T} T_{i t}+\beta_{R E} R E_{i t}+\beta_{Q U A L} Q U A L_{i t}+\beta_{T R I B} T R I B_{i t}+ \\
& \beta_{A F} A F_{i t}+\beta_{I M} I M_{i t}+\varepsilon_{i t}
\end{aligned}
$$

Conforme a descrição das variáveis anteriormente expostas e a suas respectivas fundamentações teóricas; resume-se, na Tabela 1, os resultados esperados dos sinais dos coeficientes de regressão estimados no ajuste do modelo que se mostrar estatisticamente mais adequado.

Tabela 1: Relação esperada entre variável dependente e variáveis preditoras

\begin{tabular}{lll}
\hline Coeficiente de Regressão & Variável & Sinal Esperado \\
\hline & Oportunidade de Investimento & + \\
& Tamanho & - \\
& Regulamentação & - \\
Qualidade da Empresa & + \\
& Desp. Tributária & + \\
Alavancagem Financeira & - \\
Instabilidade macroeconômica & + \\
\hline
\end{tabular}

Nota. Fonte: Elaboração própria. 


\section{APRESENTAÇÃo E ANÁlise dos RESUltados}

Antes de adentrar no propósito central desta parte do texto é importante frisar que as análises e os testes estatísticos apresentados ao longo desta seção foram realizados com o auxílio do pacote estatístico $\boldsymbol{R}$-project, cuja licença é livre para fins acadêmicos.

\subsection{Modelo OLS Pooling}

Após coletados os dados e realizado os ajustes e cálculo de variáveis independentes necessários, iniciou-se o ajuste dos modelos de regressão múltipla. A Tabela 2, apresentada os coeficientes de regressão, suas respectivas estatísticas $t$, os coeficientes de correlação $\boldsymbol{R}^{2}$ e $\boldsymbol{R}^{2}$ ajustado, e a estatística $\boldsymbol{F}$ para o modelo ajustado por meio do método dos mínimos quadrados pooling.

Tabela 2: Estimativas e testes do modelo OLS Pooling

\begin{tabular}{lllll}
\hline Coeficientes & Estimate & Std. Error & t-value & $\operatorname{Pr}(>|\mathrm{t}|)$ \\
(Intercept) & 116.3841 & 3.7726 & 30.8496 & $<2.2 \mathrm{e}-16^{* * *}$ \\
OI & 0.3254 & 0.2328 & 1.3977 & 0.16234 \\
$\mathrm{~T}$ & -4.9726 & 0.2832 & -17.5569 & $<2.2 \mathrm{e}-16^{* * *}$ \\
RE & -8.9136 & 1.2282 & -7.2575 & $5.314 \mathrm{e}-13^{* * *}$ \\
QUAL & -0.0022 & 0.0026 & -0.8477 & 0.3967 \\
TRIB & 0.0214 & 0.0221 & 0.9706 & 0.3318 \\
AF & -0.0106 & 0.0047 & -2.2563 & $0.0241 *$ \\
IM & 2.0422 & 1.2558 & 1.6263 & 0.1040 \\
\hline
\end{tabular}

R-Squared: 0.1622

Adjusted R-squared: 0.16165

F-statistic: 65.7398 on 7 and 2377 DF, p-value: $<2.22 \mathrm{e}-16$

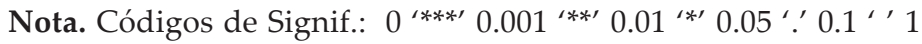

Fonte: Elaboração própria.

Como observado na Tabela 2, no ajuste do modelo de regressão via OLS pooling, as variáveis: tamanho, regulamentação do setor e alavancagem financeira se mostram estatisticamente significantes na predição da variação na proporção de endividamento de curto prazo das empresas observadas. Os sinais dos respectivos coeficientes de regressão estimados são coerentes com as predições teóricas 
consideradas na construção deste estudo. Ressalta-se, entretanto, que tais coeficientes podem não ser consistentes, visto que o método utilizado desconsidera a correlação serial inerente às observações em série temporal, como feito pelo estudo.

\subsection{Estimadores pelo modelo de Efeitos fixos}

A Tabela 3, disposta abaixo, apresenta os coeficientes de regressão, suas respectivas estatísticas $t$ os coeficiente de correlação $\boldsymbol{R}^{2}$ e $\boldsymbol{R}^{2}$ ajustado, e o resultado do teste $\boldsymbol{F}$ do modelo ajustado pelo método dos efeitos fixos. Como exposto por Greene (2003), na formulação do modelo de efeitos fixos, assume que as diferenças entre as unidades observadas, no presente caso, as empresas, poderia ser capturada pelas diferenças dos termos constantes.

Adicionalmente, foi realizado o teste para avaliar se os efeitos fixos das empresas eram ou não iguais. Tal teste, como descrito por Greene (2003), testa a hipótese nula de que os efeitos fixos estimados são iguais, situação na qual os coeficientes do modelo estimado pelo método OLS Polling seriam eficientes. Como observado na Tabela 4, aceitou-se a hipótese alternativa de que os efeitos individuais das empresas foram capturados pelos respectivos termos constantes. $\mathrm{O}$ resultado deste teste implica que os coeficientes de regressão estimados pelo método dos efeitos fixos são mais consistentes do que os estimados pelo método OLS Polling.

Tabela 3: Estimativas e testes dos modelos de Efeitos Fixos

\begin{tabular}{ll|l|l|l}
\hline Coeficientes & Estimate & Std. Error & $\mathrm{t}$ value & $\operatorname{Pr}(>|\mathrm{t}|)$ \\
\hline OI & 1.1365 & 0.6039 & 1.8819 & 0.059994. \\
T & -3.8521 & 0.7942 & -4.8500 & $1.33 \mathrm{e}-06^{* * *}$ \\
QUAL & 0.0009 & 0.0020 & 0.4482 & 0.6540 \\
TRIB & 0.0010 & 0.0174 & 0.0593 & 0.9526 \\
AF & -0.0267 & 0.0118 & -2.2471 & $0.0247^{*}$ \\
IM & 2.4028 & 0.9114 & 2.6364 & $0.0084^{* *}$ \\
\hline
\end{tabular}

R-Squared: 0.02652

Adj. R-Squared: 0.022161

F-statistic: 9.04917 on 6 and 1993 DF, p-value: 8.7911e-10

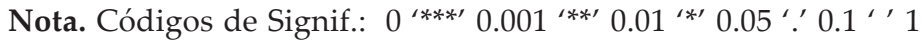

Fonte: Elaboração própria 
Como apresentado pela Tabela 3, o método dos efeitos fixos estimou coeficientes de regressão que suportam as predições teóricas que deram causa a este estudo. Sendo que os coeficientes das variáveis: Oportunidade de Investimento (OI), Tamanho (T), Alavancagem financeira (AF) e Instabilidade Macroeconômica (IM) impactam a variável dependente, sendo estatisticamente significantes, e corroborando as predições teóricas consideradas por este trabalho. $\mathrm{Ou}$ seja, via observação dos resultados dos testes $t$, podemos concluir que tais variáveis explicam alguns dos motivos pelos quais empresas optam pela emissão ou contratação de uma maior proporção de endividamento de curto prazo.

Tabela 4: Teste F para igualdade dos efeitos fixos estimados

\begin{tabular}{lllll}
\hline Teste & Estatística & DF1 & DF2 & p-value \\
\hline F & 7.2759 & 384 & 1993 & $<2.2 \mathrm{e}-16$ \\
\hline
\end{tabular}

Nota. Fonte: elaboração própria

\subsection{Estimadores pelo modelo de Efeitos Aleatórios}

Alternativamente, foi também estimado o modelo de efeitos aleatórios, com o objetivo de verificar a presença aleatoriedade e independência dos efeitos individuais, situação na qual os coeficientes estimados por este método seriam eficientes e consistentes. A Tabela 05, apresentada adiante, dispõe as estimativas dos coeficientes de regressão, suas respectivas estatísticas $t$, os coeficientes de correlação $\boldsymbol{R}^{2}$ e $\boldsymbol{R}^{2}$ ajustado, e o resultado do teste $\boldsymbol{F}$. (Tabela 5).

Quatro coeficientes de regressão estimados via o modelo dos efeitos aleatórios mostram-se estatisticamente significativos na predição da variação da proporção do endividamento de curto prazo das empresas observadas. A diferença, em relação ao modelo de efeitos fixos é a de que, neste caso, o variável Oportunidade de Investimento (OI) deixa de ser significativa e a variável regulamentação (RE) passa a sê-lo, assumindo sinal coerente com as hipóteses subjacentes que lastreiam a presente análise. 
Tabela 5: Estimativas e testes do modelo de Efeitos Aleatórios

\begin{tabular}{lllcl}
\hline Coeficientes & Estimate & Std. Error & $\mathrm{t}$ value & \multicolumn{1}{c}{$\operatorname{Pr}(>|\mathrm{t}|)$} \\
\hline (Intercept) & $1.0720 \mathrm{e}+02$ & $6.1270 \mathrm{e}+00$ & 17.4958 & $<2.2 \mathrm{e}-16^{* * *}$ \\
OI & $3.5129 \mathrm{e}-01$ & $2.3991 \mathrm{e}-01$ & 1.4642 & 0.1432 \\
$\mathrm{~T}$ & $-4.3394 \mathrm{e}+00$ & $4.6390 \mathrm{e}-01$ & -9.3542 & $<2.2 \mathrm{e}-16^{* * *}$ \\
RE & $-8.8486 \mathrm{e}+00$ & $2.4009 \mathrm{e}+00$ & -3.6856 & $0.0002 * * *$ \\
QUAL & $4.5178 \mathrm{e}-04$ & $2.0138 \mathrm{e}-03$ & 0.2243 & 0.8225 \\
TRIB & $4.2333 \mathrm{e}-03$ & $1.7190 \mathrm{e}-02$ & 0.2463 & 0.8054 \\
AF & $-1.1289 \mathrm{e}-02$ & $4.7818 \mathrm{e}-03$ & -2.3608 & $0.0183 *$ \\
IM & $2.3059 \mathrm{e}+00$ & $9.0655 \mathrm{e}-01$ & 2.5436 & $0.0110 *$ \\
\hline
\end{tabular}

R-Squared : 0.094046

Adj. R-Squared : 0.093731

F-statistic: 35.1357 on 7 and $2377 \mathrm{DF}, \mathrm{p}$-value: $<2.22 \mathrm{e}-16$

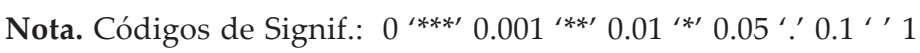

Fonte: Elaboração própria.

Com o objetivo de decidir quais dos modelos, de efeitos fixos ou de efeitos aleatórios, melhor se ajustam, em parte, às suas respectivas suposições, realizou-se o teste de Hausman, sob a hipótese nula de que os efeitos individuais não são correlacionados com as variáveis independentes. O resultado do teste é apresentado na Tabela 6, sob o qual rejeita-se a hipótese nula de que os efeitos fixos são não correlacionados com as variáveis preditoras. Por esse resultado, pôde-se concluir que as estimativas dos coeficientes estimados via modelo de efeitos fixos são consistentes e as estimativas dos coeficientes de regressão do modelo de efeito aleatório não são.

Tabela 6: Teste de Hausman

\begin{tabular}{lll}
\hline Chisq & Df & $p$-value \\
\hline 14.1916 & 6 & 0.02757 \\
\hline
\end{tabular}

Nota. Fonte: Elaboração própria

Dados os testes apresentados ao longo desta seção, conclui-se que apenas os resultados do modelo de regressão de efeitos fixos 
podem ser interpretados com maior rigor estatístico. Em que se destaca que os resultados corroboram o valor preditivo de diversas hipóteses construídas com base em teorias de imperfeições do mercado e aspectos econômicos conjunturais.

Desde modo, os achados da pesquisa indicam que quanto mais oportunidades de investimento tem certa empresa (He \& Xiong, 2012; Myers, 1977), mais ela opta por endividamento de curto prazo. O tamanho da empresa também impacta a proporção de seu endividamento de curto prazo. Corroborando os achados de Rauh (2006), nossos resultados evidenciam que quanto maior for a empresa (Ozkan, 2000; Smith Jr \& Warner, 1979; Whited, 1992), menos ela opta por endividamento de curto prazo. Adicionalmente, foi observado que quanto mais alavancada é a empresa (Nakamura et al., 2011), mais seu endividamento será composto por fontes de financiamento de longo prazo. Por fim, em congruência com resultados apresentados por Choi et al. (2018) e Almeida et al. (2009), os testes indicam significância estatística para variável de controle instabilidade macroeconômica, captando, deste modo, o efeito dos consequentes problemas de oferta de crédito sobre a estrutura financeira das empresas brasileiras.

\section{Conclusões}

Visando identificar fatores que impactam a decisão sobre o prazo de contração de dívidas de companhias brasileiras não financeiras, este estudo respaldou-se em teorias que incorporam em seus delineamentos questões relativas às imperfeições de mercado (Barclay \& Smith Jr, 1995; Flannery, 1986; Myers, 1977). O principal apelo de tais teorias é o de explicar que as decisões sobre a estrutura financeira das empresas são influenciadas por vários fatores, especialmente quando estão presentes problemas decorrentes de assimetria informacional e dos conflitos de agência.

Para isso, este trabalho observou 386 companhias de capital aberto não financeiras, no período compreendido entre 2000 e 2011. Os dados foram estruturados em um painel não balanceado, e três modelos de regressão múltipla foram ajustados, quais sejam: um simples, pelo método dos mínimos quadrados ordinários pooling, modelo de efeitos fixos e um modelo de efeitos aleatórios. O sof- 
tware $\boldsymbol{R}$-project foi utilizado no processo de estimação dos modelos de regressão e na operacionalização de demais testes estatísticos necessários às análises realizadas.

Os resultados corroboram a maior parte das hipóteses, mostrando que tanto problemas relativos à assimetria de informação e conflitos de agência como restrições ao crédito vivenciadas pelas empresas em certos períodos de instabilidade macroeconômica são fatores relevantes na predição de uma maior proporção de endividamento de curto prazo de empresas brasileiras. Mais especificamente, quatro foram as variáveis que se mostraram estatisticamente significantes na explicação da variação do endividamento de curto prazo das empresas observadas. Assim sendo, este estudo demonstra que, como predito por (Myers, 1977) e discutido por He and Xiong (2012) e Barclay e Smith Jr (1995), empresas com crescentes oportunidades de investimento tendem a optar mais por dívidas de curto prazo. Adicionalmente, os resultados desta pesquisa também trazem evidências de que quanto maior o tamanho das empresas mais elas tendem a contratar dívidas de longo prazo, como estabeleceu Barclay e Smith Jr (1995) e fora demonstrado por Rauh (2006). Isso aconteceria pela vantagem em custo, decorrentes de economias de escala, que as grandes empresas teriam em emissões públicas de títulos de dívida de longo prazo (Barclay \& Smith Jr, 1995). Ou também pela dificuldade que pequenas empresas têm de emitir dívidas no mercado de capitais (Titman \& Wessels, 1988) ou no mercado de dívidas de longo prazo, dado a proporcional limitação no número e valor de ativos que elas podem oferecer como garantia em futuras operações de crédito (Whited, 1992). Com ressaltado por (Ozkan, 2000), e corroborados pelos resultados do presente trabalho, tais aspectos aumentariam as chances de empresas pequenas recorrerem mais a fontes de financiamento (dívida) de menor prazo de maturidade.

As variáveis de controle Alavancagem financeira e Instabilidade macroeconômica são também estatisticamente significativas na explicação do prazo do endividamento das empresas observadas. Como predito, a primeira afeta negativamente o endividamento de curto prazo, tal resultado é coerente com trabalhos que demonstrado que crises econômicas impactam maturidade do endividamento de empresas (Almeida et al., 2009; Choi et al., 2018). A Alavancagem 
financeira também tem efeito negativo, como pavimentado por teorias que consideram o risco de falência como aspecto crucial na determinação da estrutura de capital das empresas (Myers, 1984). Tais resultados mostram que quanto mais alavancadas são as empresas mais elas optam por endividamento de longo prazo. Já a variável instabilidade macroeconômica capturou o efeito da escassez de crédito de longo prazo de tais períodos sobre a estrutura financeira das empresas observadas, demonstrando, portanto, ser um aspecto ambiental importante na explicação da estrutura de capital de empresas brasileiras no período observado.

Por outro lado, os achados demonstram que as variáveis regulamentação e qualidade da empresa, não afetaram o prazo de endividamento das empresas observadas, como predito por Flannery (1986). Tais evidências podem, entretanto, ter duas motivações: ou representarem de fato uma anomalia às predições teóricas; ou as proxys utilizadas para capturar tais dimensões não são adequadas para esse propósito de pesquisa. Deixando, esta observação, uma sugestão para futuras pesquisas que incorporem em suas análises proxys alternativas para tais variáveis preditoras.

É válido ressaltar que apesar de parcialmente coerente com as predições teóricas, o modelo ajustado e analisado apresenta baixo coeficiente de correlação o que pode indicar a omissão de variáveis importantes para explicação do fenômeno em foco. Alguma direção no sentido de melhorar a robustez de tais modelos é dada por Huang, Tan, and Faff (2016), que avaliaram o impacto do excesso de confiança do CEO da empresa sobre o perfil do endividamento. Os autores demonstram que tal variável afeta positivamente a proporção de endividamento de curto prazo das empresas analisadas pelo estudo.

No geral, os resultados são consistentes com as teorias que fundamentam o trabalho. Deste modo, eles indicam que a forma como foi estrutura a análise produzira resultados teoricamente mais coerentes do que os evidenciados por outros estudos brasileiros que se destinaram a investigar o mesmo fenômeno, como os de Rochman et al. (2009) e de Nakamura et al. (2011). Por essa razão, espera-se que o presente estudo contribua para o desenvolvimento da agenda de pesquisa dedicada a compreender e explicar os motivos pelos quais empresas optam ora por endividamento de curto prazo ora 
por fontes de financiamentos de longo prazo, para além do que tem sido feito por estudos fundamentados unicamente nos riscos de falência e problemas de liquidez.

\section{REFERÊNCIAS}

AKERLOF, G. A. (1978). The market for "lemons": Quality uncertainty and the market mechanism. Uncertainty in Economics (p. 235-251): Elsevier.

ALMEIDA, H., CAMPELLO, M., LARANJEIRA, B., \& WEISBENNER, S. (2009). Corporate debt maturity and the real effects of the 2007 credit crisis. National Bureau of Economic Research.

BARCLAY, M. J., \& SMITH JR, C. W. (1995). The maturity structure of corporate debt. The Journal of Finance, 50(2), 609-631.

BARNEA, A., HAUGEN, R. A., \& SENBET, L. W. (1980). A rationale for debt maturity structure and call provisions in the agency theoretic framework. The Journal of Finance, 35(5), 1223-1234.

BRICK, I. E., \& RAVID, S. A. (1985). On the relevance of debt maturity structure. The Journal of Finance, 40(5), 1423-1437.

CHOI, J., HACKBARTH, D., \& ZECHNER, J. (2018). Corporate debt maturity profiles. Journal of financial economics, 130(3), 484-502.

COASE, R. H. (1937). The nature of the firm. Economica, 4(16), 386-405.

DIAMOND, D. W., \& HE, Z. (2014). A theory of debt maturity: the long and short of debt overhang. The Journal of Finance, 69(2), 719-762.

FLANNERY, M. J. (1986). Asymmetric information and risky debt maturity choice. The Journal of Finance, 41(1), 19-37.

GREENE, W. H. (2003). Econometric analysis: Pearson Education India.

HE, Z., \& XIONG, W. (2012). Rollover risk and credit risk. The Journal of Finance, 67(2), 391-430.

HUANG, R., TAN, K. J. K., \& FAFF, R. W. (2016). CEO overconfidence and corporate debt maturity. Journal of Corporate Finance, 36, 93-110.

JENSEN, M. C., \& MECKLING, W. H. (1976). Theory of the firm: Managerial behavior, agency costs and ownership structure. Journal of financial economics, 3(4), 305-360.

KANE, A., MARCUS, A. J., \& MCDONALD, R. L. (1985). Debt policy and the rate of return premium to leverage. Journal of Financial and Quantitative Analysis, 20(4), 479-499.

MYERS, S. C. (1977). Determinants of corporate borrowing. Journal of financial economics, $5(2), 147-175$.

MYERS, S. C. (1984). The capital structure puzzle. The Journal of Finance, 39(3), 574-592. 
NAKAMURA, W. T., JUCÁ, M. N., \& BASTOS, D. D. (2011). Estrutura de maturidade das dívidas das empresas brasileiras: um estudo empírico. RAC-Revista de Administração Contemporânea, 15(2).

OZKAN, A. (2000). An empirical analysis of corporate debt maturity structure. European Financial Management, 6(2), 197-212.

RAUH, J. D. (2006). Investment and financing constraints: Evidence from the funding of corporate pension plans. the Journal of Finance, 61(1), 33-71.

ROCHMAN, R. R., LAUREANO, G. L., \& EID JR, W. (2009). Determinantes dos endividamentos de curto e longo prazos das empresas brasileiras. Paper presented at the IX Encontro Brasileiro de Finanças.

SMITH JR, C. W. (1986). Investment banking and the capital acquisition process. Journal of financial economics, 15(1-2), 3-29.

SMITH JR, C. W., \& WARNER, J. B. (1979). On financial contracting: An analysis of bond covenants. Journal of financial economics, 7(2), 117-161.

TITMAN, S., \& WESSELS, R. (1988). The determinants of capital structure choice. The Journal of Finance, 43(1), 1-19.

WHITED, T. M. (1992). Debt, liquidity constraints, and corporate investment: Evidence from panel data. The Journal of Finance, 47(4), 1425-1460.

Recebido em: 25-5-2019

Aprovado em: 30-7-2019

Avaliado pelo sistema double blind review.

Disponível em http://mjs.metodista.br/index.php/roc 